\title{
Enumerando las causas de la impunidad. Reflexiones para iniciar una estrategia antimpunidad ${ }^{*}$
}

\author{
Listing the Causes of Impunity. \\ Reflections to Start an Anti-Impunity Strategy \\ Listando as causas da impunidade. \\ Reflexões para iniciar uma estratégia anti-impunidade
}

\section{LUIS DANIEl VÁZQUEZ VALENCIA ${ }^{* \star}$}

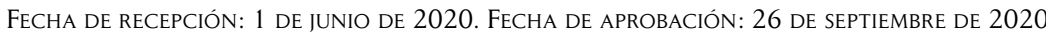

Doi: https://doi.org/10.12804/revistas.urosario.edu.co/sociojuridicos/a.9190

Para citar este artículo: Vázquez Valencia, L. D. (2021). Enumerando las causas de la impunidad. Reflexiones para iniciar una estrategia antimpunidad. Revisa de Estudios Socio-Jurídicos, 431-464. https://doi.org/10.12804/revistas. urosario.edu.co/sociojuridicos/a.9190

\section{RESUMEN}

Este artículo da respuesta a la siguiente pregunta: ¿qué elementos debemos ordenar y mapear como parte del diagnóstico antes de iniciar una estrategia antimpunidad? Como paso previo a la formulación de esta estrategia, se propone trabajar en tres aspectos: 1) identificar el tipo de responsabilidad donde se dio la impunidad, 2) delimitar los órganos estatales donde se quiere incidir y 3) determinar cuáles son las causas específicas de la impunidad que afectan a dichos órganos.

Palabras clave: impunidad; tipos de responsabilidad; causas de la impunidad; política antimpunidad; estrategias antimpunidad.

* El artículo no ha sido presentando en un congreso ni ha sido escrito para alguna ponencia.

** Profesor-investigador del Instituto de Investigaciones Jurídicas de la UNAM México, Ciudad de México. Correo electrónico: Lvazquez@flacso.edu.mx. ORCID: https://orcid. org/0000-0001-8695-6879 


\section{ABSTRACT}

This article answers the following question: What elements should we order and map, as a diagnosis, before starting an anti-impunity strategy? I propose to work on three aspects as a preliminary step to the formulation of an anti-impunity strategy: 1) to identify the type of accountability that you want to combat, 2 ) to define the government offices where you want to influence, and 3) determine the specific causes of impunity that affect those offices.

Keywords: Impunity; types of accountability; causes of impunity; anti-impunity policy; anti-impunity strategies.

\section{RESUMO}

Este artigo responde à seguinte questão: quais elementos devemos ordenar e mapear como parte do diagnóstico antes de iniciar uma estratégia anti-impunidade? Como passo preliminar para a formulação de uma estratégia anti-impunidade, propõe-se trabalhar em três aspectos: 1) identificar o tipo de responsabilidade onde ocorreu a impunidade; 2) delimitar os órgãos estaduais onde se deseja influenciar; e 3) determinar as causas específicas da impunidade que afetam tais órgãos.

Palavras-chave: impunidade; tipos de responsabilidade; causas da impunidade; política anti-impunidade; estratégias anti-impunidade. 


\section{Introducción}

Existen conceptos amplios de impunidad, como el desarrollado en el índice global de impunidad (2020). En dicho índice se mide la impunidad a partir de las dimensiones estructural, funcional y de derechos humanos tanto dentro de los sistemas de seguridad como de justicia. Bajo esta medición, la impunidad incluye indicadores como policías por cada 100 mil habitantes, personas frente a tribunales entre el número de fiscales y de jueces, el porcentaje de personas encarceladas sin sentencia, mediciones sobre personal de reclusorio e, incluso, datos sobre protección del derecho de integridad de las personas (LeClercq E Rodríguez, 2020).

Existen también conceptos mucho más acotados de impunidad, como el desarrollado por la organización Impunidad Cero (2020): “La impunidad es la falta de castigo ante un delito o la imposibilidad de ser sancionado por la falta de legislación". La Organización de Naciones Unidas (ONU) se acerca más a este tipo de conceptos minimalistas. En el Conjunto de principios para la protección y la promoción de los DDHH mediante la lucha contra la impunidad (2005) se la define como

la inexistencia, de hecho o de derecho, de responsabilidad penal por parte de los autores de violaciones, así como de responsabilidad civil, administrativa o disciplinaria, porque escapan a toda investigación con miras a su inculpación, detención, procesamiento y, en caso de ser reconocidos culpables, condena a penas apropiadas, incluso a la indemnización del daño causado a sus víctimas (ONU, 2005, p. 6).

El primer principio del mismo documento se refiere a la obligación del Estado de luchar contra la impunidad. Al respecto establece:

La impunidad constituye una infracción de las obligaciones que tienen los Estados de investigar las violaciones, adoptar medidas apropiadas respecto de sus autores, especialmente en la esfera de la justicia, para que las personas sospechosas de responsabilidad penal sean procesadas, juzgadas y condenadas a penas apropiadas, de garantizar a las víctimas recursos eficaces y la reparación de los perjuicios 
sufridos, de garantizar el derecho inalienable a conocer la verdad y de tomar todas las medidas necesarias para evitar la repetición de dichas violaciones (ONU, 2005, p. 7).

En este artículo se toma una aproximación minimalista de la impunidad. La impunidad es la ausencia de sanción frente a una acción ilegal. Desde este concepto, se tornan relevantes tres términos: la comisión de la ilicitud, la asignación de responsabilidad y la sanción. La comisión de la ilicitud supone una obligación -establecida en algún documento normativo- de acción o de omisión a cargo de una persona. Cuando dicha obligación no se cumple, se genera la responsabilidad que puede ser de diferentes tipos: penal, civil, administrativa, laboral o de derechos humanos. ${ }^{1}$ Así, se entiende por responsabilidad la generación de una posible sanción por el incumplimiento de una obligación de acción o de omisión establecida en una norma.

Sin embargo, la aplicación de la sanción no es automática. Puede suceder que la acción ilegal exista, que se establezca una responsabilidad clara frente al acto ilegal, pero que la sanción no se aplique. En la medida que se actualiza la responsabilidad, se espera que exista la sanción correspondiente a la persona que cometió el acto ilícito. Cuando esto no sucede, estamos frente a la impunidad (tabla 1).

Tabla 1. E1 proceso de la impunidad

\begin{tabular}{|l|l|l|}
\hline \multicolumn{1}{|c|}{ Acción ilegal } & \multicolumn{1}{c|}{ Responsabilidad } & Aplicación de la sanción / impunidad \\
\hline $\begin{array}{l}\text { Incumplimiento de } \\
\text { una obligación de } \\
\text { acción o de omisión } \\
\text { establecida en la norma. }\end{array}$ & $\begin{array}{l}\text { Actualización de } \\
\text { alguno o varios tipos } \\
\text { de responsabilidad. }\end{array}$ & $\begin{array}{l}\text { La persona es sancionada, } \\
\text { no hay impunidad. }\end{array}$ \\
\cline { 3 - 3 } & $\begin{array}{l}\text { La persona no es sancionada, } \\
\text { hay impunidad. }\end{array}$ \\
\hline
\end{tabular}

América Latina es la región del mundo que tiene la mayor percepción de impunidad, como se observa en las mediciones construidas por el World Justice Project (WJP) (figura 1). 


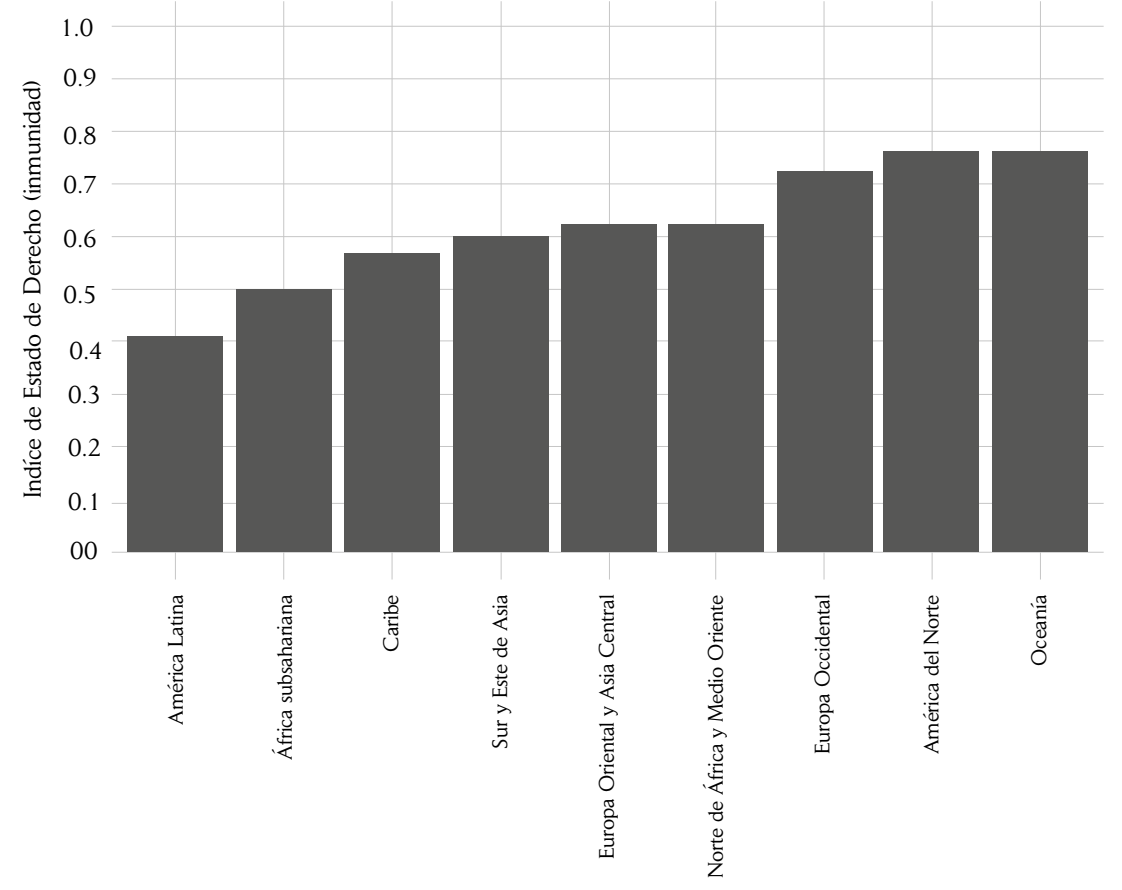

Fuente: elaboración propia con datos del WJP.

Al interior de América Latina encontramos un alto nivel de variación que va de El Salvador, Honduras y Bolivia, que son los países peor ubicados, a Chile, Uruguay, Nicaragua y Costa Rica, que están al otro lado de la figura 2.

La impunidad es un fenómeno social que impacta tanto la construcción del Estado de derecho de América Latina, como la calidad de las democracias latinoamericanas. Además, la impunidad se vincula con violaciones a los derechos humanos (Vázquez, 2020; Vázquez \& Ortiz, 2020). Pese a ello, la investigación sobre las causas de la impunidad se encuentra muy poco desarrollada, lo que se observa cuando se le compara con otros males que aquejan a la región, como la corrupción o la violencia. ¿Por qué nos interesa tan poco el estudio de la impunidad?²

2 Aquí me refiero en específico al desarrollo del concepto y mecanismos causales de la impunidad. Lo que sí hay, y mucho, son estudios sobre la ineficacia del sistema penal y las falencias de las policías de investigación y de los fiscales. En menor medida, se ha desarrollado también el campo de las instituciones de derechos humanos lo que da cuenta de la impunidad 


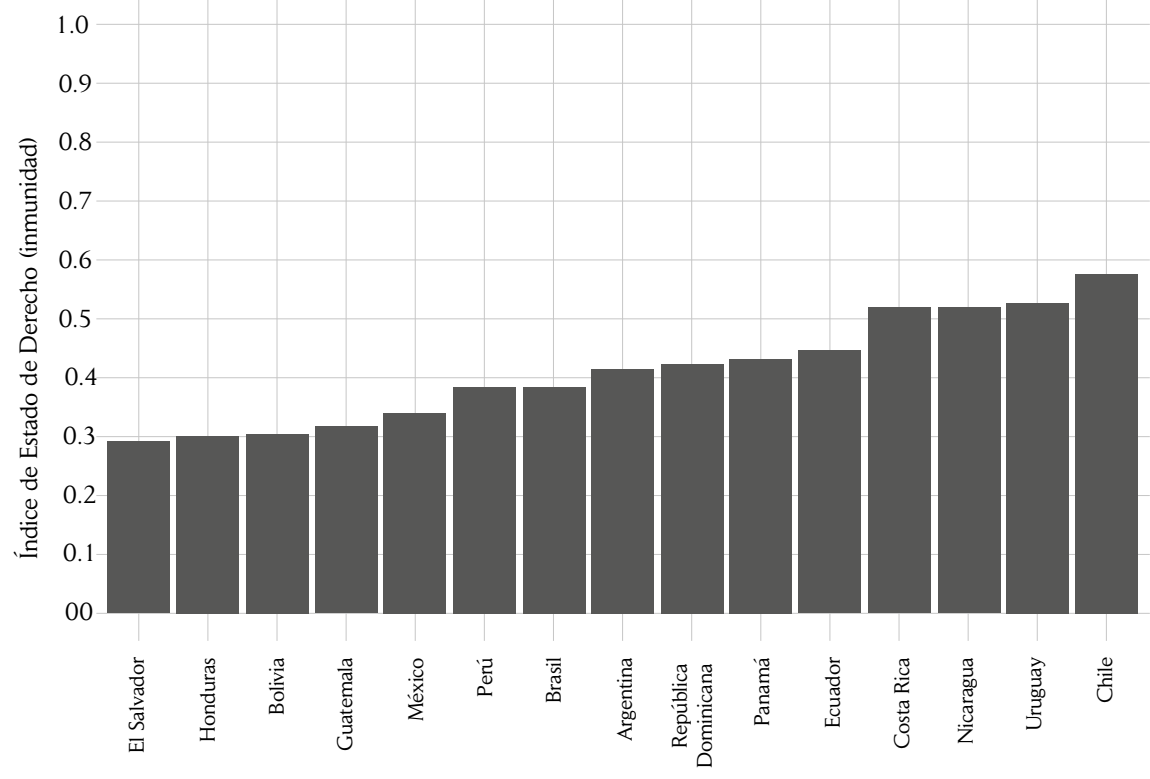

Fuente: elaboración propia con datos del WJP.

La ausencia de sanción frente a una acción ilícita es un tema directamente relacionado con la sociología jurídica (Ansolabehere, 2019; Estévez, 2019; García, 2010; Fariñas 1998). Una de las principales preguntas que se ha intentado responder en esta disciplina es ¿por qué las normas jurídicas no se cumplen? Uno de los enfoques y dilemas más conocidos en este marco es la confrontación entre facticidad y validez que nos propone Habermas (1998). En particular, nos interesa la interacción externa que se puede construir entre la facticidad y la validez, el autor la describe explicando que:

La autocomprensión normativa puede quedar desmentida por hechos sociales que intervienen en el sistema jurídico desde fuera. Facticidad y validez guardan aquí una relación externa, porque ambos momentos, es decir, por un lado las implicaciones de sentido de

en esa materia. Hay también un amplio desarrollo sobre lo que es la política judicial. Pero en ningún caso se analizan estos fenómenos en el marco de los estudios de la impunidad. Más bien se trata de campos de estudio distintos al de la impunidad. 
derecho vigente y, por otro, las restricciones sociales a que fácticamente quedan sujetas las decisiones jurídicas, pueden describirse de forma independiente (Habermas, 1998, p. 96).

Lo que se analiza en el artículo no son las causas por las cuales las personas no cumplen con una norma. Lo que interesa es enumerar las causas por las cuales, frente a una acción ilícita, los servidores públicos obligados a establecer una sanción son omisos. El objetivo de esta enumeración es estar en condiciones de elaborar un diagnóstico sólido para poder diseñar una política pública de combate a la impunidad.

Otra de las características de los estudios de la sociología jurídica, en especial de los estudios sociojurídicos de corte anglosajón cercanos a la Ley y la sociedad (Law and society), es el uso de las herramientas y metodologías analíticas de las ciencias sociales en el fenómeno jurídico. Como se mencionó en el párrafo anterior, el sustento metodológico de esta propuesta es el análisis de las políticas públicas, en particular, la generación de diagnósticos sólidos que sirvan de sustento a la estructuración y diseño de las políticas públicas (figura 3).

Figura 3. El ciclo de vida de las políticas públicas

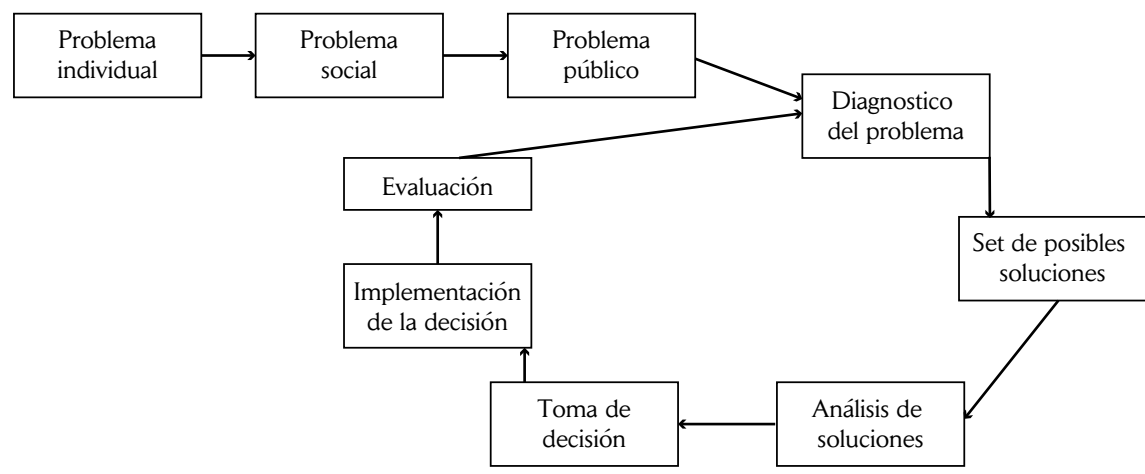

Fuente: elaboración propia con base en Vázquez y Delaplace (2011).

Una de las herramientas que se utiliza en el análisis de las políticas públicas es el ciclo de vida de las políticas, los pasos que se esperan en el desarrollo de una política desde que un problema social se convierte en problema público, hasta que la política concluye con las distintas 
formas de evaluación, para recomenzar (Vázquez \& Delaplace, 2011; Parsons, 2007).

Lo que se desarrolla en las siguientes páginas es un artículo de reflexión que orienta a los analistas y especialistas sobre impunidad en torno a los pasos que se deben realizar para desarrollar un diagnóstico adecuado que permita realizar una política pública antimpunidad. La pregunta que recorre este texto es iqué elementos debemos ordenar y mapear antes de iniciar una estrategia antimpunidad? Se deben aclarar tres aspectos:

1) ¿Cuál es el tipo de responsabilidad que queremos analizar?

2) ¿En qué órganos gubernamentales realizaremos la política antimpunidad?

3) ¿Cuáles son las distintas causas que generan el tipo de impunidad que nos interesa disminuir en el órgano concreto que estamos analizando?

No se trata de hacer una receta para combatir la impunidad, de hecho, eso sería imposible porque los criterios específicos de cualquier política pública antimpunidad dependerán de los resultados empíricos del diagnóstico. Lo que se busca es identificar la unidad de análisis donde se aplicará la política de combate a la impunidad y ordenar sus causas, no solo para hacerla analíticamente más accesible y empíricamente más observable, sino también facilitar la construcción de acciones de incidencia a fin de disminuir los niveles de impunidad. En otras palabras: se intenta ordenar el mapa de la impunidad.

\section{Los distintos tipos de responsabilidad}

Comencemos por los distintos tipos de responsabilidad. Cuando se piensa en impunidad, de forma casi inmediata, pensamos en la falta de sanción en materia penal. Y sí, esta es una forma de impunidad, pero no es la única. Hay por lo menos seis tipos de responsabilidad que pueden quedar impunes: penal, administrativa, civil (civil, mercantil y familiar), laboral, de derechos humanos y política. 


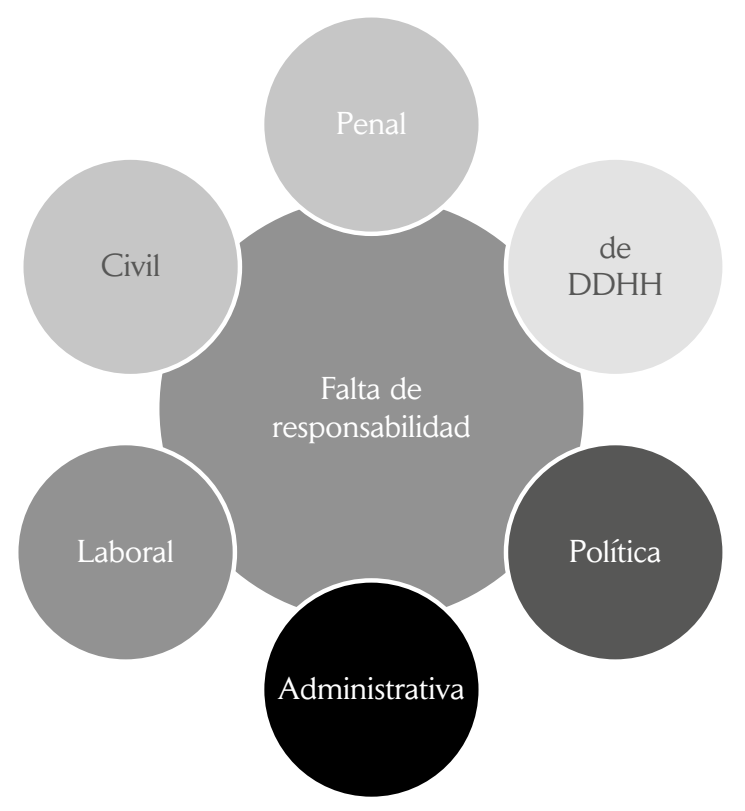

El grueso de los estudios sobre impunidad se ha concentrado en la responsabilidad penal. Se entiende por esta la generación de una posible sanción por el incumplimiento de una obligación de acción o de omisión establecida en una norma penal. La impunidad con respecto al crimen pone en el centro del análisis al sistema de justicia penal y de seguridad pública (Human RightsWatch, 1990; Acosta, 2012; Álvarez et al., 2017; Zepeda, 2017). El área de desarrollo de este tipo de responsabilidad son las fiscalías y los juzgados locales y federales en materia penal. Encontramos análisis en materia penal que utilizan indicadores como la cifra negra de denuncias de delitos, las personas que han sido víctimas de delitos o el número de sentencias obtenidas en un año, los cuales nos permiten entender esta dimensión de la impunidad. Se trabaja especialmente con el delito de homicidio, tanto por ser el de menor cifra negra, como por existir datos a nivel mundial recopilados por la Oficina de Naciones Unidas contra la Droga y el Delito ${ }^{3}$ (Zepeda $\&$

3 La base de datos de la UNDOC se puede obtener en esta página: https://www.unodc. org/unodc/en/data-and-analysis/statistics.html 
Jiménez, 2016). Siguiendo con el enfoque penal, existen otros estudios que dan cuenta de la forma en que cambian los sistemas de justicia penal y cómo los nuevos actores, así como las diferentes prácticas tanto de los entes estatales como de las organizaciones de derechos humanos y abogados activistas, pueden tener un impacto en la disminución de la impunidad (González, 2016; Gallagher, 2017). Estos dos tipos de estudio son preponderantes en esta área y se complementan. Mientras que los estudios que analizan la impunidad por medio de la construcción de indicadores se sustentan en metodologías cuantitativas y análisis estadísticos, los segundos permiten identificar los procesos que suceden al interior de las fiscalías por medio de técnicas cualitativas.

Otra línea distinta gira en torno a los costos de la impunidad. Se parte de que el crimen es una industria, la industria criminal; los delincuentes toman la opción de delinquir a partir de una evaluación de costo beneficio. Con estos criterios, ¿qué inversión sería necesaria en el sistema de seguridad y justicia para mantener la impunidad en niveles aceptables? (Gordon et al., 2011; Iglesias et al., 2012).

Vayamos ahora a la responsabilidad administrativa. Se entiende por ella la generación de una posible sanción por el incumplimiento de una obligación de acción o de omisión establecida en una norma de carácter administrativo. Tanto los gobernantes y servidores públicos como los gobernados pueden incurrir en este tipo de responsabilidad. Los segundos en aspectos como el incumplimiento de regulaciones de un negocio, por ejemplo, un restaurante o una tienda, como en el incumplimiento de permisos en actividades reguladas como las construcciones o remodelaciones. Los gobernantes y servidores públicos caen en responsabilidad administrativa cuando incumplen con sus obligaciones o no observan al pie de la letra los procesos administrativos. Aquí nos interesa la responsabilidad administrativa de los servidores públicos.

Este tipo de responsabilidad cobra especial relevancia cuando queremos observar tanto la impunidad de los actos de corrupción (Casar, 2015), que generan violaciones a los derechos humanos (Vázquez, 2018b), como la impunidad de las violaciones a los derechos humanos cometidas por agentes gubernamentales que pueden ser sancionadas tanto por la vía penal, como por la vía administrativa. 
Para este tipo de responsabilidad se diversifican los órganos - que varían de país a país- que aplican la responsabilidad. Por ejemplo, en el caso de México se cuenta con la Secretaría de la Función Pública y las contralorías locales, la Auditoría Superior de la Federación, los tribunales federal y locales de justicia administrativa y prácticamente toda la administración pública federal y local donde se realizan trámites administrativos, que tienen capacidad de sanción. Mientras que en materia penal la principal sanción (más no la única) es la privación legal de la libertad; en materia administrativa, las sanciones pueden ser apercibimientos (privados y públicos), multas, clausuras, pérdida del trabajo (para los servidores públicos) e inhabilitaciones (para servidores públicos, personas y empresas contratistas).

Miremos el tercer tipo de responsabilidad. Se entiende por responsabilidad en materia de derechos humanos la generación de una posible sanción por el incumplimiento de una obligación de acción o de omisión establecida en una norma de derechos humanos. Estas normas pueden tener un carácter nacional e internacional. El documento internacional más conocido es la Declaración Universal de Derechos Humanos que data de 1948. Entre los documentos internacionales que aplican a América Latina tenemos la Declaración Americana de los Derechos y los Deberes del Hombre y la Convención Americana sobre Derechos Humanos. En otras palabras, en la región aplican tanto el sistema universal como el interamericano. Además de estas normas internacionales, existe otro conjunto de normas nacionales (como las constituciones y las leyes emanadas de esta) que deben integrarse e interpretarse de conformidad con las normas internacionales mencionadas. En todo este conjunto normativo se encuentran las normas relacionadas con derechos humanos.

Por otro lado, en los últimos 30 años a nivel mundial se han desarrollado una serie de órganos de protección de derechos humanos, se trata de las comisiones de derechos humanos, defensorías del pueblo u Ombusdperson. Estos órganos se encargan de recibir peticiones por probables violaciones en materia de derechos humanos y de determinar en qué casos estamos frente a una violación y qué debe hacer el gobierno en turno para reparar a la víctima. Estos órganos son los entes primarios que determinan la responsabilidad en materia de derechos 
humanos. A los órganos locales habría que sumar las comisiones internacionales de derechos humanos (como la Comisión Interamericana), así como las cortes internacionales también especializadas en el tema (como la Corte Interamericana o la Corte Europea) y los distintos órganos cuasijurisdiccionales inherentes al sistema universal, como los diferentes comités de derechos humanos de la ONU. Un aspecto central para esta responsabilidad en particular es que la determinación de esta y la sanción a los autores intelectuales y materiales de la violación a los derechos humanos está desconectada. Si bien normalmente se identifica o se busca identificar a los autores materiales e intelectuales, a quien se sanciona es al órgano gubernamental donde esos servidores públicos se desempeñaban, en el caso de la responsabilidad nacional de DDHH o al Estado en su totalidad en el caso de la responsabilidad internacional de DDHH. Más que sanciones individualizadas, en este tipo de responsabilidad lo que cobra relevancia son los mecanismos de reparación integral (Center for Human Rights, 1995; González, 2003; Uggla, 2004).

La responsabilidad laboral se refiere a la generación de una posible sanción por el incumplimiento de una obligación de acción o de omisión establecida en una norma de esta materia tanto a cargo de los patrones, como de los trabajadores. Algunos de los derechos laborales se establecen en los artículos 23, 24 y 25 de la Declaración Universal de los Derechos Humanos, que incluyen: el derecho al trabajo y a su libre elección; a condiciones equitativas y satisfactorias de trabajo; a la protección contra el desempleo; a igual salario por igual trabajo; a una remuneración equitativa y satisfactoria; a fundar sindicatos y a sindicalizarse para la defensa de sus intereses; al descanso, al disfrute del tiempo libre, a una limitación razonable de la duración del trabajo y a vacaciones periódicas pagadas, y a un seguro en caso de desempleo, enfermedad, invalidez, viudez, vejez u otros casos de pérdida de sus medios de subsistencia por circunstancias independientes a su voluntad. El espacio de litigio de este tipo de responsabilidad son las juntas local y federal de conciliación y arbitraje.

Estamos frente a la responsabilidad civil cuando se genera una posible sanción por el incumplimiento de una obligación de acción o de omisión establecida en una norma civil. Incluyo en este conjunto 
normativo a las materias civil en estricto sentido, a la mercantil y a la familiar. Casos claros de las dos primeras son el incumplimiento de obligaciones establecidas en contratos civiles o mercantiles. En cambio, la responsabilidad en materia familiar está relacionada con las obligaciones establecidas entre cónyuges, de madre y padre a hijes y viceversa. El espacio ordinario de este tipo de responsabilidad son los juzgados civiles tanto locales como federales. El incumplimiento de cualquiera de esas obligaciones sin la sanción correspondiente dará cuenta de la impunidad en materia civil.

Quise dejar hasta el final la responsabilidad política debido a las dudas que puede causar la idea de establecerla tanto como responsabilidad, como en los tipos de impunidad. Como en los casos anteriores, la responsabilidad política supone la generación de una posible sanción por el incumplimiento de una obligación de acción o de omisión establecida en una norma política. Y aquí empieza el problema, ¿cuáles podrían ser las normas políticas? Por ejemplo, ¿los deberes a cargo de los gobiernos establecidos en las constituciones? ¿Los programas políticos elaborados en las campañas electorales?

De inicio, mantenemos la premisa mínima: no se trata de deberes morales, la responsabilidad y expectativas de acción a cargo de los gobiernos se encuentran establecidas en las leyes, más aún, en las constituciones. Se trata de formulaciones muy generales como el concepto de democracia que se desarrolla en el artículo tercero de la constitución mexicana, como "un sistema de vida fundado en el constante mejoramiento económico, social y cultural del pueblo" (Constitución, artículo 3) o los objetivos de la soberanía establecidos en el artículo 39 de la misma constitución: "Todo poder público dimana del pueblo y se instituye para beneficio de este" (Constitución, artículo 39). Bajo esta lógica, la obligación constitucional a cargo del gobierno de turno es que la gente tenga un constante mejoramiento económico, social y cultural como expresión de beneficio del pueblo.

Si bien tenemos expectativas constitucionales de la acción de los gobiernos, lo que no tenemos son especificaciones de las acciones u omisiones esperadas, en este caso, por los cargos o puestos específicos de los gobernantes. Por ello, no estamos frente a responsabilidad penal, administrativa o de derechos humanos, sino frente a responsabilidad política. 
Encontramos la responsabilidad política en dos mecanismos de accountability o rendición de cuentas: la vertical ${ }^{4}$ y la social. ${ }^{5}$ La primera se refiere al premio o castigo que recibe un gobernante en su intento por reelegirse ya sea por persona o por partido. Lo esperable es que aquellos políticos, que cometen actos que se alejan de esas expectativas políticas establecidas a nivel constitucional, sean castigados - ya sea ellos o sus partidos- en las urnas (Vázquez, 2007; 2008; 2009). Si el gobernante hizo un mal trabajo, pero no es castigado (el ciudadano vuelve a votar por él o por su partido), entonces no se actualiza la responsabilidad política.

La rendición de cuentas social se refiere a la inclusión (o no) del conjunto de demandas de diversos actores sociales como los movimientos sociales, las ONG, estudiantes, ciudadanes independientes y grupos religiosos, por mencionar algunos. Cada uno de estos grupos tiene diversos recursos políticos como las marchas, mítines, ocupaciones de inmuebles o la huelga. Si el gobernante toma una decisión que vulnera a un movimiento o grupo social y este no reacciona, no se activa la responsabilidad política vía rendición de cuentas social.

Dentro de esta también podemos dar cuenta de la formación de tendencias en la opinión pública a partir de una esfera pública deliberativa. Si un gobernante toma una decisión contraria a los intereses de la mayoría o de un grupo en situación de vulnerabilidad y no se activa una reacción crítica en los medios de comunicación, estamos frente a un acto de impunidad de la responsabilidad política a través de la ausencia de la rendición de cuentas social.

Los tipos de responsabilidades que hemos desarrollado no son excluyentes. Un mismo acto puede desencadenar diferentes tipos de responsabilidad. Por ejemplo, un grupo de policías que hayan realizado una desaparición forzada pueden ser sancionados tanto en materia penal, como administrativa, de derechos humanos y política. Las tres

4 En torno a la redición de cuentas vertical son útiles: Arnold, 2002; Bernstein, 1989; Dunn, 1999; Fearon, 1999; Ferejohn, 1999; Przeworki et al., 1999; Vázquez 2007, 2008 y 2009. La rendición de cuentas horizontal, pesos y contrapesos o Estado de derecho estaría en todas las demás expresiones de la impunidad que han quedado mencionadas.

5 Los creadores del concepto de redición de cuentas social son Peruzzoti y Smulovitz (2002). 
primeras son evidentes, la desaparición forzada es un delito, ${ }^{6}$ por lo que se activa la responsabilidad penal. Los policías son servidores públicos que, si desaparecen a alguna persona, se alejan de sus deberes como tales, lo que actualiza la responsabilidad administrativa. ${ }^{7}$ Por último, la desaparición forzada es una grave violación a los derechos humanos, ${ }^{8}$ lo que detona la responsabilidad en esa materia.

Además de las responsabilidades penal, administrativa y de derechos humanos, la responsabilidad política se puede dar ya sea mediante la formación de una opinión pública contraria al gobierno del que forman parte esos policías, condenando la desaparición forzada y, por ende, generando un voto de castigo para ese gobierno en las siguientes elecciones. Si, además, el gobierno en turno emitió un boletín de prensa afirmando que las personas desaparecidas eran delincuentes peligrosos, se activa también la responsabilidad civil por el daño al honor que puede causar una declaración de este tipo con respecto a las víctimas a fin de minimizar la desaparición forzada realizada por los policías.

Considerando que uno de los principales objetivos del régimen democrático es controlar las decisiones políticas vinculantes del gobierno para evitar que vulneren los derechos de las personas (Vázquez 2007; 2008; 2009), lo ideal en un régimen democrático es que todas las formas de responsabilidad funcionen. Lamentablemente esto no es así. Partimos del hecho de que la impunidad siempre existirá. Incluso el mejor equipo de investigadores tendrá algún caso sin resolver. Por ende, cuando se planifican políticas a partir de documentos como la Estrategia Nacional de Seguridad Pública o el Plan Nacional de Persecución Penal en México, lo que se determina es cuáles serán los principales

6 El artículo 27 de la Ley General en Materia de Desaparición Forzada establece: "comete el delito de desaparición forzada de personas, el servidor público o el particular que, con la autorización, el apoyo o la aquiescencia de un servidor público, prive de la libertad en cualquier forma a una persona, seguida de la abstención o negativa a reconocer dicha privación de la libertad o a proporcionar la información sobre la misma o su suerte, destino o paradero".

7 En México, la responsabilidad administrativa por la desaparición de personas se establece en la Ley general en la materia.

8 Existen sendos tratados internacionales en los sistemas universal e interamericano en materia de desaparición forzada: la Convención Internacional para la Protección de Todas las Personas contra la Desaparición Forzada y la Convención Interamericana sobre Desaparición Forzada de Personas. 
objetivos de la política antimpunidad en materia penal, en el caso de esos dos documentos.

Hasta aquí el primer paso que deberían realizar las personas que están construyendo una estrategia o una política antimpunidad. Lo primero que deben preguntarse es ien qué tipo de responsabilidad nos interesa incidir: penal, administrativa, de derechos humanos, civil, laboral o política? La pregunta es algo más que un debate teórico o conceptual. Las diferencias en las respuestas a la pregunta anterior tendrán como consecuencia distinciones en la unidad de análisis.

\section{Identificar la unidad de análisis para simplificar la incidencia}

Como vimos en el ejemplo sobre la desaparición forzada, un mismo acto ilícito puede acarrear cinco tipos de responsabilidad: penal, administrativa, de derechos humanos, política y civil. ¿Queremos incidir en todas o solo en algunas de ellas?

No es recomendable pensar solamente en la impunidad de un fenómeno concreto: combatir la impunidad de la tortura, de los homicidios, de las desapariciones forzadas, de la corrupción, de la violación a la vida libre de violencia, por mencionar algunos. Se torna necesario combinar el fenómeno social cuya impunidad nos interesa combatir con el tipo de responsabilidad que nos interesa aplicar.

Figura 5. Distintos programas de política antimpunidad relacionados con la desaparición forzada

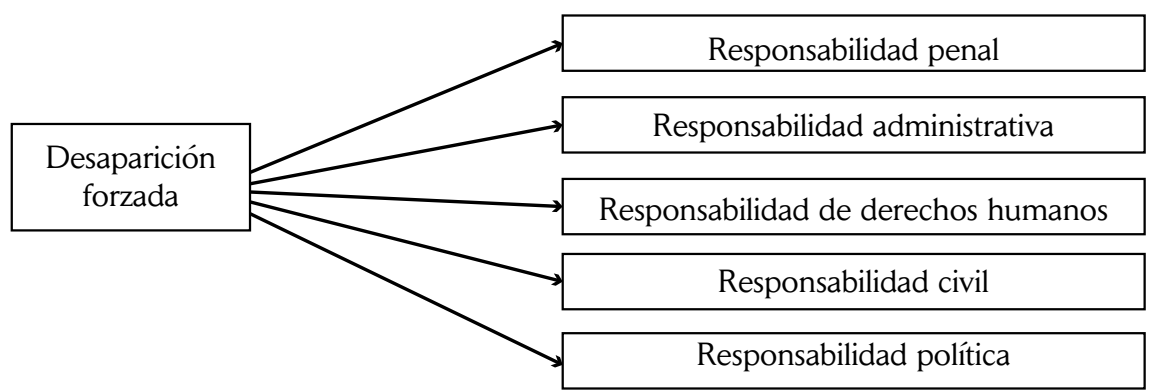


Así, por ejemplo, podemos pensar en una política para combatir la impunidad en las desapariciones forzadas a partir de cinco estrategias o políticas específicas antimpunidad.

La discusión no es solo teórica, conceptual o analítica. Dependiendo de la respuesta podemos determinar cuál será nuestra unidad de análisis, la organización administrativa, legislación, incentivos y demás elementos organizacionales y de regulación sobre los que se quiere incidir. Por ejemplo, si se quiere incidir en la impunidad en materia penal relacionada con la desaparición forzada, la unidad de análisis serán las fiscalías, en particular si hay fiscalías especializadas, los policías de investigación y los jueces en materia penal que conocen de estos casos. ¿Qué hacen? ¿Qué dejan de hacer? ¿Dónde están las lagunas? ¿Dónde están los incentivos? ¿Cuáles son las tensiones? En breve, ¿por qué no se sanciona la desaparición forzada en una región determinada? En cambio, podemos mantenernos en el mismo fenómeno -la desaparición forzada- pero lo que queremos combatir es la impunidad administrativa. De ser así, la unidad de análisis donde se quiere incidir cambia por completo. Nos interesaremos en las contralorías internas, la secretaría de la función pública y les jueces administrativos, por dar algunos ejemplos.

Hasta aquí, la propuesta para definir la unidad u organización donde se analizará la impunidad supone la combinación de una problemática social (la desaparición forzada) y un tipo de responsabilidad. Pero también es posible que, en general, se quiera diseñar una estrategia antimpunidad de la totalidad de un tipo de responsabilidad. Por ejemplo, una estrategia para combatir la impunidad en la responsabilidad penal o administrativa o de derechos humanos. Se puede. El punto es que entre más general sea la delimitación del tipo de responsabilidad que se quiere combatir, más amplia será la unidad de análisis y, por ende, más complejo el fenómeno de impunidad y el diseño de la política antimpunidad.

En cualquier caso, recomiendo que se especifiquen, al menos, los siguientes elementos en la construcción de la unidad de análisis donde se pretende aplicar una política para combatir la impunidad:

1) El tipo de responsabilidad que interesa combatir (penal, administrativa, de derechos humanos, civil, laboral o política). 
2) Considerando un país federal como el caso de México, la distribución de competencias cobra mucha relevancia. Por lo que también es importante determinar si se actuará con una unidad federal, estatal o municipal. ${ }^{9}$ Sin embargo, en esta elección, es importante enfatizar las relaciones que permitan que la impunidad se mantenga gracias a las interacciones entre las instituciones de esos tres niveles. Por ejemplo, podemos elegir el nivel municipal para analizar la impunidad administrativa. En la medida que mucho del gasto municipal proviene de la federación y de la entidad federativa, no bastará con analizar las instituciones municipales encargadas de las sanciones administrativas, tendremos que incluir las estatales y federales, pero solo en lo que respecta a la investigación y sanción municipal.

3) Teniendo claro el tipo de responsabilidad y el nivel de actuación política (federal, estatal o municipal), es importante que se haga la especificación de las organizaciones estatales que interesa analizar, de todas aquellas que están relacionadas con el tipo de impunidad en donde se busca incidir.

4) Una vez que tenemos mapeadas todas las organizaciones involucradas en la política antimpunidad que queremos diseñar, es importante que también podamos identificar los actores al interior de esas organizaciones, las actividades que legalmente les corresponde realizar, así como analizar empíricamente qué es lo que realmente hace cada uno de ellos. En este diagnóstico mucho más empírico debemos dar cuenta de incentivos positivos y negativos que nos lleven a la impunidad, así como la cultura organizacional ${ }^{10}$ que permea en cada una de las instituciones y, en su caso, en el sistema en su conjunto.

Con estos elementos, tendremos claro cuál es la unidad de análisis compuesta por las distintas organizaciones, actores, regulaciones, acciones, incentivos y cultura organizacional. Estamos en aptitud de realizar el diagnóstico correspondiente para poder pensar, posteriormente, cómo

9 La diferencia entre los organismos federales, estatales y municipales deriva de la competencia territorial que tienen: todo el país, las entidades federativas o provincias o solo en el territorio municipal.

10 En el siguiente acápite desarrollaremos el concepto de cultura organizacional, que cobra mucha relevancia para analizar las causas de la impunidad. 
incidir en el diseño de una política antimpunidad. Uno de los aspectos centrales del diagnóstico será identificar empíricamente cuáles son las principales causas de la impunidad.

\section{Identificar las causas de la impunidad para determinar los mecanismos de incidencia}

Una vez tenemos claro el tipo de responsabilidad en el que vamos a incidir y la unidad de análisis con la que vamos a trabajar, estamos en condiciones de construir un diagnóstico con la siguiente pregunta: ¿por qué no se genera la sanción correspondiente cuando alguna persona incumple con la ley generando algún tipo de responsabilidad (penal, civil, laboral, de DDHH, política o administrativa)? Enfatizo el inicio de la pregunta: por qué. Se trata de construir un diagnóstico empírico que nos permita mirar una relación causal. En otras palabras, lo que vamos a buscar en el diagnóstico son las causas de la impunidad.

Sin ánimo exhaustivo, vale la pena tener en mente al menos estas seis causas de la impunidad. Podría haber muchas más, pero al menos tenga en cuenta que estas seis pueden estar presentes en el fenómeno de impunidad que está analizando:

1) Impunidad por macrocriminalidad.

2) Impunidad por relaciones políticas.

3) Impunidad por cultura organizacional corrupta.

4) Impunidad por cultura organizacional burocratizada.

5) Impunidad por normalización.

6) Impunidad por incapacidad.

La impunidad puede tener múltiples causas. Estas distintas causas de la impunidad no son excluyentes. Puede suceder que un órgano de justicia se encuentre afectado por todas ellas al mismo tiempo o solo por una o dos. Lo importante es poder identificar qué causas generan la impunidad, porque la solución de cada una de ellas supone acciones de política pública diferenciadas. 
Miremos rápidamente cada una de las seis causas de la impunidad. Comencemos por la impunidad que se gesta desde arriba, desde la esfera política. Aquí tendremos dos causas de impunidad: por macrocriminalidad y por relaciones políticas. Para decirlo brevemente, en estos casos, incluso si se tuvieran servidores públicos profesionales y capacidades suficientes, la impunidad se gestaría en las altas esferas políticas. La clase política puede combatir la impunidad, pero no quiere.

Una red de macrocriminalidad ${ }^{11}$ está conformada por tres estructuras: empresariales, políticas y criminales, que además se tornan mucho más flexibles y difusas. En palabras de Salcedo y Garay (2016):

Las formas más complejas de crimen se caracterizan por (i) la variedad de agentes sociales involucrados, (ii) la diversidad de interacciones entre agentes y (iii) los efectos sobre las instituciones y la sociedad. Estas tres características básicas permiten identificar a la más compleja entre redes criminales comparadas. La primera característica, la variedad de agentes, se refiere a que en la red participan funcionarios públicos y agentes del sector privado, adicionales a los criminales que por supuesto operan en la red (p. 5).

En la medida que una de las estructuras es política (federal, estatal o municipal), habrá una distorsión de las decisiones políticas vinculantes que servirán a los intereses específicos de la red, en la que existe una demanda explícita de impunidad para todos sus miembros. Esta demanda de impunidad se materializa si policías, fiscalías o poderes judiciales son parte de la red (Vázquez, 2019b).

11 Al utilizar el término red de macrocriminalidad tenemos un preconcepto del Estado que es importante explicitar. 'Estado' funciona como sinónimo de 'gobierno', conformado por múltiples organizaciones que pueden tener relaciones de cooperación, conflicto o indiferencia entre ellas. Incluyen a los poderes ejecutivo, legislativo y judicial, así como a los órganos autónomos. Supone que el Estado tiene cierta autonomía relativa y está sometido a una tensión estructural a partir de dos elementos: el hecho de que es un instrumento de dominación pero, al mismo tiempo, es una promesa no inocua de bienestar. Estos dos aspectos conforman al campo político donde se dirimen los conflictos socioestatales (Cantamutto et al., 2017). Tanto la autonomía relativa como la promesa no inocua de bienestar dotan a esta idea estatal de un elemento normativo (semejante al liberal) con el que algunas corrientes marxistas y de antropología política no estarían del todo de acuerdo. Una de las principales motivaciones que detonan esta investigación es la necesidad de reconstruir esta idea normativa estatal en el caso de México. 
No se requiere controlar al órgano de investigación o sanción en su totalidad, basta con tener el control de los puestos clave. Por ejemplo, una red de macrocriminalidad más grande y poderosa puede incluir entre sus miembros a gobernadores, fiscales generales o jefes de policía. Una red mucho más pequeña puede incluir solo a ciertos fiscales clave, jefes intermedios de policía o algunos jueces. En la medida que parte de la clase política pertenezca a la red de macrocriminalidad, los miembros de la red saben que pueden cometer cualquier delito con total impunidad: licitaciones amañadas, extorsiones, desapariciones, homicidios. Por ejemplo, de acuerdo con Vázquez y Ortiz (2018), la impunidad se relaciona con los niveles de desaparición de personas y de desplazamiento forzado interno:

1) Se puede vincular a la impunidad con el $58 \%$ de personas desaparecidas en Veracruz en 2016, 51 \% de personas desaparecidas en Puebla y $29 \%$ en Michoacán en ese mismo año, todas entidades federativas de México (Vázquez \& Ortiz, 2018).

2) Se puede vincular a la impunidad con el $35 \%$ del total de hogares desplazados forzosamente en Michoacán durante 2016, con el 46\% en Jalisco y el $41 \%$ en la Ciudad de México en ese mismo año, también entidades federativas de México (Vázquez \& Ortiz, 2018).

Cuando pensamos en redes de macrocriminalidad, inmediatamente pensamos en los grandes cárteles de las drogas. Pero también se puede tratar de redes de macrocriminalidad de corrupción con fines electorales. Por ejemplo, en México es muy común que se realicen sistemáticos actos de corrupción por medio de empresas fantasma y licitaciones amañadas a fin de desviar fondos públicos para la construcción de redes clientelares y el financiamiento ilegal de campañas electorales. Este es uno de los principales pendientes a investigar especialmente en la campaña presidencial del 2012 del candidato ganador Enrique Peña Nieto en México. Aquí la estructura gubernamental tiene un mayor peso y el objetivo es ganar la elección para que se mantenga tanto la red misma, como la promesa de impunidad por medio del mantenimiento del gobierno (Vázquez, 2018a). En estos casos, la impunidad también será garantizada para los miembros de la red de macrocriminalidad, 
pero los actos de corrupción impunes impactarán en los derechos económicos y sociales de las personas. Por ejemplo, de conformidad con Vázquez (2019b), la impunidad puede costar hasta 7181 USD en el PIB per cápita a nivel mundial, impacta también en una pérdida de hasta 4.7 años de escolaridad promedio a nivel mundial y de $0.21 \%$ de población con rezago educativo por cada punto de impunidad en México. La impunidad también impacta en los derechos a una vida digna, a la alimentación y a la salud, los cuales se pueden mirar a través de la esperanza de vida que se puede ver reducida hasta en 3.7 años a nivel mundial.

La solución a la impunidad provocada por redes de macrocriminalidad parece evidente: lo que necesitamos es desmantelar esa red de macrocriminalidad y descapturar a los órganos encargados de la investigación y la sanción. Si esto no se hace, la impunidad permanecerá.

Supongamos que la impunidad por macrocriminalidad no es el problema que aparece en la unidad de análisis que estamos diagnosticando. Sin embargo, nos topamos con la otra causa de impunidad que viene de la clase política: la impunidad por relaciones políticas. El problema de la impunidad se complejiza cuando se entremezcla con intereses de grupos políticamente relevantes. Cuando esto sucede, estamos frente a la causa de la impunidad por relaciones políticas. El entrelazamiento de grupos políticamente relevantes, cuyos intereses están condicionados al mantenimiento de la impunidad, genera redes de corrupción que detonan lo que se conoce eufemísticamente como "falta de voluntad política". El problema será la omisión en la investigación y sanción y, en el peor de los casos, el uso de la acción estatal para perpetuar la impunidad. ${ }^{12}$

Lo que se pone en juego en la impunidad por relaciones políticas es la falta de autonomía - de iure o de facto-de los órganos encargados de la investigación y de la sanción. Esto se facilita si, además, tampoco

12 En el informe elaborado por Open Society (2015) junto con diversas organizaciones de derechos humanos se concluye que la comisión de violaciones a derechos humanos es una política deliberada del Estado, lo que se observa en aspectos como: 1) su omisión en regular adecuadamente el uso de la fuerza y 2) la ausencia de investigación y procesamiento por la comisión de crímenes atroces de los agentes federales (p. 63). Este es el punto de partida que utiliza el informe para determinar que las violaciones graves en materia de derechos humanos en México no solo son generalizadas, sino también sistemáticas, es decir, fueron planificadas y son sostenidas por el gobierno en turno. 
se cuenta con independencia en los servicios forenses ${ }^{13} \mathrm{y}$ de protección de testigos. ${ }^{14}$ En la medida que estos órganos no sean autónomos, el poder ejecutivo (federal o local) podrá decidir a quién se investiga y se sanciona y a quién no. Se trata de un uso politizado de la justicia.

Hay que ser cuidadoso de no confundir el uso politizado de la justicia con la construcción de una política antimpunidad o contra el delito. En la medida que siempre habrá algo de impunidad y que los recursos estatales son limitados, todo gobierno necesita crear una estrategia de seguridad y un plan de persecución penal para determinar a qué tipo de actos ilegales se les dará prioridad para ser investigados y sancionados. Estas decisiones deben ser públicas y sometidas a diversos controles tanto ante el congreso, como por mecanismos ciudadanos. Pero la formulación de una política y estrategia que combate el crimen a fin de priorizar recursos es algo totalmente distinto a la politización de la justicia. En esta última, lo que se determina es no investigar a alguien en especial por órdenes del presidente o de algún otro alto funcionario. La historia de México está plagada de ejemplos de uso político de la justicia con omisiones y desviaciones en las investigaciones de la fiscalía. Probablemente el caso más claro al momento de escribir estas líneas es la promesa presidencial: olvido no, pero perdón sí. Y, con ella, la iniciativa del poder ejecutivo de no investigar ningún crimen cometido por los más altos funcionarios de los gobiernos anteriores (Vázquez, 2020).

13 De acuerdo con una encuesta levantada a todos los expertos forenses de la PGR en 2002 , el $23 \%$ de ellos temían a las represalias de los agentes del orden público cuando su evaluación pericial señalaba la existencia de lesiones físicas posiblemente derivadas de la tortura o malos tratos, y el $18 \%$ indicaron que habían sido obligados por dichos agentes o sus superiores a cambiar los resultados de sus informes periciales. En 2009, el personal médico de la PGR informó a una delegación del Subcomité para la Prevención de la Tortura que, con frecuencia, tenían que modificar los informes médicos de conformidad con órdenes expresas de los funcionarios de la PGR. En 2012, el Comité contra la Tortura de las Naciones Unidas expresó su preocupación con respecto a los informes de presencia militar durante los reconocimientos médicos (Open Society, 2016, p. 123).

14 En 2012 se promulgó una legislación federal sobre la protección de testigos por medio de la cual se creó el Centro Federal de Protección a Personas. Por ley, dicho centro cuenta con autonomía técnica y operativa, lo que ofrece una mejor estructura para la protección de testigos. Sin embargo, mientras la función de protección de testigos permanezca bajo la administración de la PGR, carece de garantías de seguridad y es proclive a la manipulación y la corrupción (Open Society, 2016, p. 126). Una de las principales solicitudes de un conjunto de ONG, académicos y activistas que presentaron una propuesta integral de justicia transicional al presidente Andrés Manuel López Obrador durante finales del 2018 y principios del 2019 incluyó precisamente la creación de un mecanismo de protección a víctimas y testigos. 
Hasta aquí las dos causas de impunidad que provienen de los más altos funcionarios. Si estamos frente a ellos, el principal problema es de voluntad política: la clase política no quiere combatir la impunidad, de hecho, forma parte de ella. Vayamos ahora a las causas de impunidad que se generan desde abajo, en los propios órganos de investigación y sanción, en los servidores públicos (mandos medios y bajos). En estos casos podemos decir que la clase política quiere, pero no puede combatir la impunidad.

Comencemos por la impunidad por una cultura organizacional corrupta. En este caso, las instituciones encargadas de la investigación y sanción pueden contar con los recursos suficientes, no es un problema de capacidades estatales. Incluso, puede suceder que se cuente también con la voluntad política de los mandos altos, pero los mandos medios y bajos operan a partir de dinámicas contrarias a los objetivos de la institución.

En estos casos, los operadores de los distintos sistemas de justicia (penal, administrativa, civil, de derechos humanos, política) actúan en el marco de una cultura organizacional que desvía a la institución de sus objetivos primordiales. Definamos lo que entendemos por cultura organizacional. A partir de Driskill y Laird (2011), la cultura se constituye por las redes de significado que tenemos de nosotros mismos y que son construidas de forma interactiva. Podemos observar esta idea de cultura en un país, pero también podemos delimitar la observación a lo que sucede al interior de una o varias de las organizaciones que conforman nuestra unidad de análisis de conformidad con lo desarrollado en la sección anterior. Bajo este criterio, cada organización es única y construye sus propias creencias, sus mecanismos para reforzarlas, sus héroes, sus celebraciones, su historia; lo que impacta en sus prácticas, hábitos y actitudes. La cultura organizacional incide tanto en el flujo de información de los niveles más altos a los ejecutores, como en la forma de implementar las órdenes. La forma de aproximarnos a la identificación de esta cultura organizacional es como lo hacen los antropólogos sociales: interactuando, analizando los documentos emanados de la organización, participando en su actividad cotidiana, pero también en sus ritos y rituales. 
Cuando esta cultura organizacional construya y normaliza prácticas de corrupción, estaremos frente a la impunidad por una cultura organizacional corrupta. Por ejemplo, si hay un contexto de corrupción que afecta a toda la cadena del proceso de justicia, entonces el objetivo institucional se desvía, ya no es investigar violaciones a derechos humanos y sancionar a los culpables, sino obtener una tasa de ganancia para los operadores del sistema de justicia. Si hay investigación y sanción, será de forma aleatoria y por la activación de otros incentivos.

También puede suceder que tengamos una cultura organizacional burocratizada. Aquí también tenemos un desvío de los objetivos institucionales, no se investiga ni se sanciona a los responsables de la comisión de actos ilegales. Pero no porque los servidores públicos sean corruptos, sino porque las dinámicas institucionalizadas al interior de la propia organización tienden a otros objetivos, a otros lugares lejanos de la procuración y la administración de la justicia. Por ejemplo, debido a la falta de incentivos apropiados que impulsen al personal a realizar los objetivos institucionales, puede suceder que los servidores públicos tengan como criterio simplemente el menor esfuerzo, lo que convierte a la investigación en un simple proceso burocrático de papeleo. Aquí, la pregunta es icómo detonar el entusiasmo de los servidores públicos en torno a la concreción de los objetivos institucionales?

Tanto en la causa de impunidad por una cultura organizacional corrupta, como en la burocrática lo que se requiere es identificar las estructuras de incentivos formales e informales, positivos y negativos que constituyen esa cultura organizacional. Hecho eso, lo relevante es crear un nuevo sistema de incentivos para modificarlos y revertirlos. En la cultura organizacional corrupta, es relevante acompañar el cambio de incentivos con procesos de investigación y sanción. No se descarta en ambos la refundación de las instituciones de investigación en casos en donde la cultura organizacional corrupta o burocrática es extrema y muy arraigada, de tal forma que es menos costoso crear instituciones nuevas que tratar de modificar los patrones en las ya existentes.

Vayamos a la quinta causa de impunidad construida desde abajo, en los servidores públicos: la impunidad por normalización. La explicaré con el caso de la práctica generalizada de la tortura. De acuerdo con el relator de la ONU contra la tortura, su práctica en México es 
generalizada (Méndez, 2014). Esta calificación jurídica quiere decir que la tortura se practica por todos los cuerpos policiales (municipales, estatales, federales, el ejército y la marina), en todo el territorio (no es una práctica local o regional), y con un muy alto grado de impunidad (Méndez, 2014). Estos mismos tres elementos son indicadores de que la tortura es parte de la cultura organizacional de la política de seguridad, entendida como las prácticas, hábitos, actitudes y valores que comparten, en nuestro caso concreto, los cuerpos de seguridad. En la medida que la tortura es normalizada dentro de las prácticas institucionales, es entendible que sea tolerada, que no sea investigada ni sancionada, y que todo esto se convierta en un incentivo que la perpetúa. Este es el punto central, cuando una conducta ilegal es normalizada al interior de la burocracia estatal, se convierte en una práctica tolerada, por lo que no es investigada ni sancionada (Méndez, 2014; Open Society, 2016; Amnistía, 2001; Bacio, 2008).

La tortura como parte de la cultura organizacional (como método de "investigación") ${ }^{15}$ permite entender cómo se gesta la impunidad. En muchos países, la policía y la fiscalía trabajan en estrecha colaboración, lo cual puede dar pie a que los fiscales no actúen con imparcialidad e independencia cuando tienen que investigar denuncias contra la policía. Otro problema a la hora de garantizar investigaciones prontas e imparciales es que, incluso cuando la fiscalía u otras autoridades judiciales emprenden $u$ ordenan emprender investigaciones sobre torturas o malos tratos policiales, el propio cuerpo de policía es el encargado de llevar a cabo las tareas de investigación. En numerosos países, esto supone una merma de la integridad de estas investigaciones y afecta las decisiones sobre el posible procesamiento de los responsables (Amnistía Internacional, 2001, p. 78; Bacio, 2008).

La normalización de ciertas prácticas ilegales puede ir más allá de los servidores públicos y llegar hasta la clase política. En estos casos, se cruzarán dos causas de la impunidad: por relación política y por normalización. El caso de la tortura sigue siendo útil para ejemplificarlo.

15 Con este ejemplo no pretendemos validar, en ningún sentido, la práctica de la tortura ni con respecto a los argumentos más profundos que apelan a la dignidad de la persona ni a los más superficiales que explican por qué la tortura es un mal método de investigación: una persona torturada dirá cualquier cosa que quiera ser escuchada por el torturador. 
Cuando la tortura se utiliza como instrumento de control social -nos dice Amnistía Internacional (2011, p. 12) - existen fuerzas poderosas interesadas en mantener la impunidad. En su análisis sobre la dictadura de Brasil, Reiss (2000) observa que el mismo general Geisel, antes de morir, admitió claramente que la tortura de presos políticos fue un recurso del que echó mano el Estado por encontrarse en peligro. Un recurso acaso indigno, pero que los otros también habrían usado de haber sido vencedores, adujo el general. Hoy nadie duda que en Brasil durante los años 60 y 70 la tortura fue sistemática (Reis, 2000, p. 90). En la mayoría de los países en los que la tortura se comete con impunidad, el problema no es la carencia de leyes adecuadas, sino la falta de voluntad política para afrontar los delitos cometidos por funcionarios del Estado u otras personas en el poder (Amnistía Internacional, 2001, p. 63).

La secuencia que sigue la relación entre la normalización y la impunidad es la siguiente: 1) se normaliza una acción ilegal, 2) se genera una tolerancia por parte del órgano encargado de la investigación a esa acción ilegal y 3) la consecuencia de la normalización y la tolerancia es la ausencia de investigación. ¿Qué hacer frente a la impunidad por normalización? Lograr que lo "normal" (torturar, por ejemplo) deje de serlo.

Vamos a la última causa de impunidad. Supongamos que realizamos el análisis empírico de la unidad de análisis que nos interesa, a partir del tipo de impunidad que estamos investigando y no aparecieron ninguna de las cinco causas anteriores de la impunidad: ni por macrocriminalidad ni por relaciones políticas ni por cultura organizacional corrupta o burocrática ni por normalización. De ser así, tenemos buenas noticias: se alinean los intereses políticos con los de los mandos medios y bajos. En estos casos puede suceder que ambos (políticos y servidores públicos) quieran, pero no puedan. Estaremos frente a la impunidad por incapacidad estatal.

La impunidad por incapacidad estatal se da cuando el Estado no cuenta con los diferentes recursos (económicos, humanos, tecnológicos o de cualquier otro tipo) necesarios para poder investigar y sancionar las conductas ilegales que nos interesa analizar. Por ejemplo, a partir de la declaración de guerra contra el narcotráfico en México en diciembre del 2006, tenemos alrededor de 300 mil homicidios (INEGI, s. f.) y más de 70 mil personas desaparecidas sin considerar la cifra negra (Registro 
Nacional de Personas Desaparecidas y No Localizadas, s. f.). Aunque la Fiscalía Nacional y las 32 fiscalías locales tuvieran toda la intención de investigarlos, no cuentan con las capacidades para hacerlo.

La impunidad por incapacidad estatal supone que hay autonomía estatal y voluntad política para abatir la impunidad. Sin embargo, lo que no hay son las herramientas suficientes para lograrlo. Estas debilidades pueden estar relacionadas con diferentes aspectos como una mala normativa, la falta de presupuesto, la insuficiencia de personal clave como fiscales o peritos, la ausencia de conocimiento para saber cómo investigar ese tipo de delitos (knowhow), por mencionar algunos.

En estos casos, el problema se resuelve de forma relativamente sencilla -reitero, suponiendo que hay voluntad política para que exista una fiscalía políticamente autónoma y técnicamente capaz- ${ }^{16}$ basta con realizar un plan progresivo para dotar a las fiscalías de las capacidades y recursos necesarios y suficientes para combatir la impunidad.

\section{Pasos para elaborar un diagnóstico previo al diseño de una política antimpunidad}

A manera de conclusión, tenemos claros los tres pasos que debemos realizar para elaborar un diagnóstico previo al diseño de una política pública antimpunidad. El primer paso es determinar cuál es el tipo de responsabilidad sobre la cual se construirá la política antimpunidad: penal, civil, laboral, de derechos humanos, política, administrativa u otra. Esto es algo más que un debate conceptual, es el paso previo para poder identificar las organizaciones, instituciones y actores que conformarán la unidad de análisis con la cual trabajaremos la formulación empírica de un diagnóstico.

El segundo paso es delimitar cuáles son los órganos y actores que deben ser incluidos en el análisis del tipo de responsabilidad elegido. Como mencionamos líneas arriba, se puede delimitar a partir de una

16 Esto podría sonar muy sencillo, pero no lo es, para nada. Basta mirar las dificultades que se han enfrentado en México para construir una \#FiscalíaQueSirva, que sea autónoma, que tenga capacidades de investigación. 
combinación de elementos, siempre guiados por los intereses del investigador. Por ejemplo, podemos trabajar solo con un tipo de responsabilidad de los mencionados en el párrafo anterior. También podemos combinar un fenómeno social (desaparición, tortura, homicidio) con un tipo de responsabilidad o trabajar varios tipos de responsabilidad de un fenómeno social específico. Lo importante es tener claro el punto de partida para poder identificar las organizaciones que se encuentran involucradas. En esta última determinación, vale la pena considerar, al menos, el tipo de impunidad, el nivel (federal, local o municipal), la enumeración de las instituciones estatales involucradas y la identificación de los actores relevantes al interior de esas organizaciones.

Finalmente, el tercer paso es la realización del diagnóstico en donde se deben considerar, por lo menos, las seis causas de la impunidad: por macrocriminalidad, por relaciones políticas, por cultura organizacional corrupta, por cultura organizacional burocratizada, por normalización o por incapacidad estatal. Dependiendo de la causa de impunidad será el trabajo que deberá desarrollarse en el diseño de la política pública en cuestión. En los siguientes puntos presento algunos brochazos (aún no son pinceladas) que deben terminar de especificarse a partir del diagnóstico específico elaborado en cada caso concreto:

- Si la causa de la impunidad es la macrocriminalidad, la impunidad se construye desde arriba, desde las esferas políticas y la política debe ir dirigida a desmantelar la red de macrocriminalidad y descapturar a los órganos de investigación y sanción.

- Si la causa de impunidad son las relaciones políticas, el uso político de la justicia, la impunidad se construye desde arriba y la política antimpunidad deberá construir autonomía jurídica y de facto de los órganos encargados de la investigación y la sanción.

- Si la causa de la impunidad es la cultura organizacional corrupta, la impunidad se construye desde abajo, desde los servidores públicos, y la política antimpunidad deberá buscar sancionar a los culpables de corrupción, identificar los incentivos positivos y negativos que detonan la corrupción e incidir en ellos. 
- Si la causa de impunidad es la cultura organizacional burocratizada, la impunidad se construye desde abajo, en cuyo caso, la política antimpunidad deberá identificar los incentivos positivos y negativos que generan las lógicas burocratizadas e incidir en ellos.

- Si la causa de la impunidad es la normalización, la impunidad se construye desde abajo y la política antimpunidad deberá lograr que lo "normal" (como torturar) deje de serlo.

- Si la causa de la impunidad es la falta de capacidades, la impunidad se construye desde arriba y desde abajo, la política antimpunidad deberá identificar dónde se encuentran los recursos deficitarios y realizar un fortalecimiento institucional.

Si no realizamos un diagnóstico efectivo que nos permita identificar cuáles son las causas de la impunidad, en el mejor de los casos diseñaremos una política antimpunidad que no tendrá ninguna incidencia y tiraremos a la basura una gran cantidad de recursos públicos a la par que la impunidad seguirá incólume. Pero un mal diagnóstico puede generar algo más que la nula incidencia. Por ejemplo, puede suceder que diseñemos e implementemos una política antimpunidad que enfatice la capacidad estatal (impunidad por incapacidad), cuando el órgano en cuestión en realidad no tenga problemas de capacidad, sino que la impunidad se deba a que los principales actores de ese órgano han sido capturados por una red de macrocriminalidad (Vázquez, 2019b). En estos casos, el resultado no será solo la nula incidencia, sino que se fortalecerá a un órgano que, de hecho, trabaja para el crimen. Así de grave puede ser el error en el diagnóstico y en el diseño de una política antimpunidad.

Por lo anterior, se propone que el analista siga el orden de revisión de las causas de la impunidad trabajado en la sección anterior. Vale la pena que primero se descarte que la impunidad se deba a la existencia de una red de macrocriminalidad, después a las relaciones políticas, pase luego a la cultura organizacional corrupta, a la burocratizada y a la normalización y tolerancia de conductas ilegales para dejar hasta el final la falta de capacidades y recursos estatales. Así se evitará errores graves como el mencionado en el párrafo anterior. 


\section{Referencias}

Acosta, M. (2012). El desafío de la seguridad pública y la impunidad. En Autor, La impunidad crónica de México. Una aproximación desde los derechos humanos (pp. 57-148). Comisión de Derechos Humanos del Distrito Federal.

Álvarez, M., Romero, A., Pulgarín, F., Romero, M. (2017). El valor del delito. Sistema Penal Acusatorio ¿cuánto nos cuesta? Política pública y praxis. Procuraduría General de la Nación, Instituto de Estudios del Ministerio Público y Ministerio de Justicia y del Derecho.

Amnistía Internacional. (2001). Acabar con la impunidad. Justicia para las víctimas de tortura. Amnistía Internacional.

Ansolabehere, K. (2019). Los derechos humanos en los estudios sociojurídicos. En A. Estévez \& D. Vázquez (Coords.), Los derechos humanos en las ciencias sociales. Una perspectiva multidisciplinaria (pp. 21-44). Flacso-México / CISAN-UNAM.

Arnold, D. (2002). ¿Pueden unos ciudadanos poco atentos a la política controlar a su representantes electos? Zona Abierta, (100/101), 73-98.

Bacio, J. (2008). Corruption as a violation of human rights. http://papers.ssrn. com/sol3/papers.cfm?abstract_id=1107918

Bernstein, R. (1989). El mito del control del electorado. Alianza Editorial.

Cantamutto, F,. Hernández, A., \& Vázquez, D.. (2017). Imaginar un país. América Latina, procesos constituyentes y proyecto de nación en México. Fundación para la democracia / CLACSO.

Casar, M. A. (2015). México: anatomía de la corrupción. CIDE/IMCO.

Center for Human Rights (1995). National Human Rights Institutions. A Handbook on the Establishment and Strengthening of National Institutions for the Promotion and Protection of Human Rights. Geneve: UnitedNations (Professional Training Series No. 4).

Constitución política de los Estados Unidos Mexicanos. http://www.diputados. gob.mx/LeyesBiblio/pdf/1_060320.pdf

Driskill, G., \& Laird Brenton, A. (2011). Organizational culture in action: A cultural Analysis Workbook. SAGE Publications, Inc.

Dunn, J. (1999). Situating democratic political accountability. En A. Przeworski, B. Manin, \& S. Stokes (Eds.), Democracy, accountability, and representation (pp. 329-344). Cambridge University Press.

Estévez, A. (2019). Los derechos humanos en la sociología política contemporánea: una gramática en disputa. En A. Estévez \& D. Vázquez (Coords.), 
Los derechos humanos en las ciencias sociales. Una perspectiva multidisciplinaria (pp. 139-174). Flacso-México / CISAN-UnAM.

Estrategia Nacional de Seguridad Pública (2019). México. https:// www.gob.mx/sspc/es/articulos/estrategia-nacional-de-seguridadpublica?idiom $=$ es\#: : text $=\mathrm{La} \% 20$ estrategia $\% 20$ contempla $\% 20$ la $\% 20$ creaci $\%$ C3\%B3n,la\%20seguridad $\% 20$ de $\% 20$ los $\% 20$ ciudadanos.Etext $=$ La $\% 20$ Estrategia $\% 20$ de $\% 20$ Seguridad $\% 20 \mathrm{P} \%$ C3\%BAblica,la $\% 20$ seguridad $\% 20 \mathrm{de} \% 20 \mathrm{los} \% 20$ ciudadanos

Fariñas, M. J. (1998). Sociología de los derechos humanos. En M. J. Añón, R. Bergalli, M. Calvo, \& P. Casanovas (Coord.), Derecho y sociedad (pp. 687701). Tirant lo Blanch.

Fearon, J. (1999). Electoral accountability and the control of politicians selecting good types versus sanctioning poor performance. En A. Przeworski, B. Manin \& S. Stokes (Eds.), Democracy, accountability, and representation (pp. 55-97). Cambridge University Press.

Ferejohn, J. (1999). Accountability and authority: toward a theory of political accountability. En A. Przeworski, B. Manin \& S. Stokes (Eds.), Democracy, accountability, and representation (pp. 131-153). Cambridge University Press.

García Villegas, M. (2010). Sociología y crítica del derecho. Fontamara.

Gallagher, J. (2017). The last mile problem: activists, advocates, and the struggle for justice in domestic courts. Comparative Political Studies, 50(12), 1666-1698. https://doi.org/10.1177/0010414016688001

González, E. (2016). Shifting legal visions: Judicial change and human rights trials in Latin American, Cambridge University Press.

González, L. (2003). The institution of de ombudsman. The Latin American experience. Revista IIDH, (37), 219-248.

Gordon, M., Iglesias, J. R., Semeshenko, V., \& Nadal, J.P. (2011). Crime and punishment: the economic burden of impunity. An Americas matcha report.

Habermas, J. (1998). Facticidad y validez. Sobre el derecho y el Estado democrático de derecho en términos de teoría del discurso. Trotta.

Iglesias, J. R., Semeshenko, V., Schneider, E. M., \& Gordon, M. B. (2012). Crime and punishment: Does it pay to punish? Physica A: Statistical Mechanics and its Applications, 391(15), 3942-3950.

Impunidad Cero. Quienes somos. https://www.impunidadcero.org/quienesSomos.php?id=2Et=quienes-somos

Instituto Nacional de Estadística y Geografía -INEGI-. (s. f.). Mortalidad. Cojunto de datos: Defunciones por homicidios [base de datos]. https://www.inegi.org. 
$\mathrm{mx} /$ sistemas/olap/proyectos/bd/continuas/mortalidad/defuncioneshom. asp?s=est

LeClercq, J. A., E Rodriguez, G. (2020). Índice global de impunidad 2020. Escalas de impunidad en el mundo. UDLAP.

Ley general en materia de desaparición forzada de personas, desaparición cometida por particulares y del sistema nacional de búsqueda de personas. http://www.diputados.gob.mx/LeyesBiblio/pdf/LGMDFP_171117.pdf

Méndez, J. (2014). Informe del relator especial sobre la tortura y otros tratos o penas crueles, inhumanos o degradantes. A/HRC/28/68/Add.3 ONU.

Organización de las Naciones Unidas. (2005). Conjunto de principios actualizado para la protección y la promoción de los derechos humanos mediante la lucha contra la impunidad. E/CN.4/2005/102/Add.1

Open SocietyFoundations. (2016). Atrocidades innegables. Confrontando crímenes de lesa humanidad en México. Open Society.

Ortiz, H., E Velázquez, D. (26 de octubre de 2018). El impacto de la impunidad en las desapariciones. https://www.animalpolitico.com/blog-invitado/elimpacto-de-la-impunidad-en-las-desapariciones/

Parsons, W. (2007). Políticas públicas. Una introducción a la teoría y la práctica del análisis de las políticas públicas. FLACSO-México.

Peruzzotti, E., E Smulovitz, C. (2002). Accountability social: la otra cara del control. En E. Peruzzotti \& C. Smulovitz (Eds.), Controlando la política. Ciudadanos y medios en las nuevas democracias latinoamericanas (pp. 1-39). Temas Grupo Editorial.

Plan Nacional de Persecución Penal. (2020). México. https://www.gob.mx/ fgr/documentos/plan-de-persecucion-penal

Przeworski, A., Manin, B., E Stokes, S. (1999). Elections and representation. En A. Przeworski, B. Manin, E S. Stokes (Eds.), Democracy, accountability, and representation (pp. 29-54). Cambridge University Press.

Registro Nacional de Personas Desaparecidas y No Localizadas. (s. f.). https:// versionpublicarnpdno.segob.gob.mx/Dashboard/Index

Reis, D. (2000). Sociedad, tortura y dictadura en Brasil. En I. Delgado (Ed.), Impunidad y derecho a la memoria de Pinochet a Timor (pp. 89-98). Sequitur.

Salcedo, E., E Garay, L. (2016). Macro-criminalidad. Complejidad y resiliencia de las redes criminales. Universe.

Uggla, F. (2004). The ombudsman in Latin América. Journal of Latin American Studies, (36), 423-450. https://doi.org/10.1017/S0022216X04007746 
Vázquez, D. (2007). La democracia, el populismo y los recursos políticos del mercado: déficits democráticos y neopopulismo. En Vox Populi. Populismo $y$ democracia en América Latina. Flacso.

Vázquez, D. (2008). Democracia liberal procedimental y movimientos sociales. Temas pendientes en la democracia mexicana luego del conflicto en Oaxaca. En J. Aibar E D. Vázquez (Coords.), Política y Sociedad en México. Entre el desencuentro y la ruptura (pp. 259-304). Flacso.

Vázquez, D. (2009). Democracia y mercado: viejas disputas, inuevas soluciones? Análisis y lecciones del caso argentino (1989-2008). Flacso-México.

Vázquez, D. (2018a). Mexicanstyledemocracy: a frameworkconduciveto human rightsviolation. En A. Anaya \& B Frey (Eds.), México's human rights crisis (pp. 187-206). University of Pensylvania Press.

Vázquez, D. (2018b). Corrupción y Derechos Humanos. ¿Por dónde comenzar la estrategia anticorrupción? Peter Lang.

Vázquez, D. (2019a). El impacto de la impunidad en los derechos económicos y sociales. Este País, 2-12. https://www.impunidadcero.org/uploads/app/ articulo/125/contenido/1570551204T12.pdf

Vázquez, D. (2019b). Captura del Estado, macrocriminalidad, y derechos humanos. Flacso-México / IIJ-UNAM / Fundación Böll.

Vázquez, D. (2020). Impunidad y violaciones a derechos humanos. IIJ-UNAM. En prensa.

Vázquez, D., E Delaplace, D. (2011). Public policies from a human rights perspective. A developing field. Sur. International Journal on Human Rigths, (14), 33-62.

Vázquez, D., \& Ortiz, H. (2020). Impunity and economic and social rights. Human Rights Review. https://doi.org/10.1007/s12142-020-00580-3 https:// link.springer.com/article/10.1007/s12142-020-00580-3?wt_mc=Internal. Event.1.SEM.ArticleAuthorAssignedTolssue

Vázquez, D., E Ortiz, H. (2018). Impunidad y violaciones a los derechos humanos. Costos de la Impunidad. http://www.costosdelaimpunidad.mx/wp-content/ uploads/2019/02/Impunidad-y-violaciones-a-los-DDHH-Ortiz-y-Vazquez. pdf

Zepeda, G. (2017). Indice estatal de desempeño de las procuradurías y fiscalias. Impunidad Cero. https://www.impunidadcero.org/impunidad-en-mexico/ assets/pdf/15_Impunidad_Cero_Ranking_de_procuradurias.pdf Zepeda, G., E Jiménez, P. (2016). Impunidad frente al homicidio doloso en México, (13).

World Justice Project. https://worldjusticeproject.org/ 